\title{
Research on Evaluation Method of Rail Transit Train Operation Scheme Based on DEA Method
}

\author{
Liang $\mathrm{Xu}^{\mathrm{a}}$, Haidong Liu ${ }^{\mathrm{b}}$ \\ MOE Key Laboratory for Urban Transportation Complex Systems Theory \& Technology, Beijing \\ Jiao tong University, China. \\ a16120911@bjtu.edu.cn, bhdliu@bjtu.edu.cn
}

Keywords: Data envelopment analysis, train operation scheme, evaluation, ranking.

\begin{abstract}
In this paper, we established an evaluation index system and then calculated different efficiencies of the two kinds of efficient decision-making units and the non-effective ones to evaluate and rank them synthetically. At the same time, the inherent requirements and characteristics of the Data Envelopment Analysis is also considered. The comparison between our method and the existing research verifies the reasonability and practicability of this paper. The results of the case study illustrate that the method proposed in this paper will play a guiding role in train planning comparison and selection practice.
\end{abstract}

\section{Introduction}

The passenger train operation scheme is the basic of railway organization work, which can decide passenger rail transportation service level, including train type, routes and numbers. In the meanwhile, train operation scheme evaluation can guarantee the optimal comprehensive benefits of the rail transit system and the basis of the comparison of different train operation schemes. It is a systematic work involving many factors such as economy, technology and service, which is supposed to meet the passenger demand and social responsibility and to obtain the maximum economic benefits.

Many researchers have conducted in-depth studies on the evaluation of train operation scheme. Deng [1] combines Cluster Analysis and Principal Component Analysis to reduce the number of evaluation indexes and reduce the influence of correlation among the indicators. Tao [2] uses Matrix Analysis to study the influencing factors of economic benefits of the train operation scheme. Aside, A. [3] and $\mathrm{Pu}$ [4] apply data envelopment analysis method to analyze the production efficiency based on the classification of evaluation indicators for the train operation scheme. Kulak et.al [5] compare different indicators by applying fuzzy comprehensive evaluation to train operation scheme evaluation. Xu and Cheng [6] proposed a weighted sum evaluation model and a minimum weighted relative deviation distance evaluation model; they also discuss and prove the opposite result of the two evaluation methods on the same train operation scheme, giving the application condition.

Based on the existing research results, this paper proposes a comprehensive benefit ranking evaluation model based on DEA (data envelopment analysis) method, which can solve the problem that the traditional model cannot rank all the DMUs (decision making units) and take the essential application characteristics of the DEA into consideration, which were usually ignored.

\section{Evaluation Index System Establishment}

As the basis of the comprehensive train operation scheme evaluation, the content of evaluation index system determines the rationality of the evaluation method, and it's supposed to reflect the attributes of the different aspects and the overall efficacy of the rail transit system (Qu and Xu [7]). We can study the train operation evaluation system from three aspects: economy, technology, and service. The evaluation index system of this paper is conducted from the above three aspects on the base of existing researches, giving consideration to the purpose and systematic. 
Table 1. Evaluation system of train operation scheme.

\begin{tabular}{|c|c|c|}
\hline Economy & Technology & Service \\
\hline \multirow{3}{*}{$\begin{array}{c}\text { Total cost } \\
\text { (10 thousand yuan) }\end{array}$} & Average train travel distance $(\mathrm{km})$ & \multirow{2}{*}{$\begin{array}{c}\text { Average passenger travel } \\
\text { time(hour) }\end{array}$} \\
\hline & Passenger transport volume(pkm) & \\
\hline & Train marshalling & $\begin{array}{c}\text { Comfort level } \\
\text { (Fatigue recovery time) }\end{array}$ \\
\hline \multirow{2}{*}{$\begin{array}{c}\text { Total income } \\
\text { (10 thousand yuan) }\end{array}$} & Average stop times(time) & \multirow{2}{*}{ Average waiting time(minute) } \\
\hline & Number of the running trains & \\
\hline \multirow{3}{*}{ Average attendance rate(\%) } & Average travel speed $(\mathrm{km} / \mathrm{h})$ & \multirow[t]{2}{*}{ Average direct ratio(\%) } \\
\hline & Railway line capacity utilization(\%) & \\
\hline & Total train travel time(hour) & Average transfer times(time) \\
\hline
\end{tabular}

In practice, suitable indicators can be selected for different evaluation environments. For example, passenger waiting time is an essential factor in the evaluation of urban rail transit train operation scheme; in comparison, waiting time is such an unimportant element that can be neglected.

\section{Evaluation Indexes Pretreatment}

\subsection{Input and Output Index Classification.}

Since DEA method applies to the multi-input and multi-output situations, all the indexes should be classified according to the principle that the behavioral indicator that influences the DMU production is the input index and the output is generated by the DMUs, as shown in Table 2. At the same time, some unsuitable indexes can be excluded when the method is used in a certain circumstance.

Table 2. Evaluation indices input/output classification.

\begin{tabular}{|c|c|c|c|c|c|}
\hline category & \multicolumn{2}{|c|}{ Name and symbol } & category & \multicolumn{2}{|c|}{ Name and symbol } \\
\hline \multirow{11}{*}{ Input } & \multirow{2}{*}{ Total cost } & \multirow{2}{*}{$\mathrm{x} 1$} & \multirow{11}{*}{ Output } & Total income & y1 \\
\hline & & & & Average attendance rate & $\mathrm{y} 2$ \\
\hline & \multirow[b]{2}{*}{ Average train travel distance } & \multirow[b]{2}{*}{$\mathrm{x} 2$} & & Passenger transport volume & $\mathrm{y} 3$ \\
\hline & & & & Average travel speed & $\mathrm{y} 4$ \\
\hline & \multirow{3}{*}{ Train marshalling } & \multirow{3}{*}{$\mathrm{x} 3$} & & Railway line capacity utilization & y5 \\
\hline & & & & Total train travel time & y6 \\
\hline & & & & Average passenger travel time & $\mathrm{y} 7$ \\
\hline & \multirow[t]{2}{*}{ Average stop times } & \multirow[t]{2}{*}{$\mathrm{x} 4$} & & Comfort level & y8 \\
\hline & & & & Average waiting time & y9 \\
\hline & \multirow{2}{*}{ Number of the running trains } & \multirow{2}{*}{$\mathrm{x} 5$} & & Average direct ratio & $\mathrm{y} 10$ \\
\hline & & & & Average transfer times & y11 \\
\hline
\end{tabular}

\subsection{Evaluation Indexes Positive or Negative Rationalization.}

The input indexes are supposed to be negative, the smaller value the better; the output indexes are positive and the bigger value, the better. When the actual situation is inconsistent with this premise, the original indexes, such as travel time, waiting time and transfer times in this paper, are required to be transformed into the expected ones by using linear transformation or in some another method. The 
method below is applied in this paper; the original value of the rah indicator is $\mathrm{y}_{r, j}$ and the transformed value isy ${ }_{r, j}^{\prime}$, as shown in Eq. 1.

$$
\mathrm{y}_{r, j}^{\prime}=\sum_{j=1}^{n} \mathrm{y}_{r, j}-\mathrm{y}_{r, j}
$$

Where: $j=1,2, n$ and $n$ are the number of all the DMUs. It should be noted that the transformed index will be used directly to represent the original one for the convenience of description and the symbol won't be changed, that is, use the value $\mathrm{y}_{r, j}^{\prime}$ in the place of that of $\mathrm{y}_{r, j}$.

\subsection{Number of Indexes Reduction.}

Experience shows that when the number of DMUs is 2-3 times the total number of indexes, the evaluation result is accurate and reasonable enough, which is a requirement of DEA called the degree of freedom. Therefore, when this cannot be satisfied in reality, some method should be applied in the first place to reduce the number of the indexes such as selecting main indicators or weighting methods, on the premise of guarantee the positive and negative property of the indexes. This paper uses the Variation Coefficient Method to integrate the same type of indexes by weighting them, which can eliminate the impact of different dimensions and the subjective factors caused by human participation. Let $\mathrm{n}$ indicates the total number of the indexes of any DMU, and $\mathrm{X}_{i j}$ indicates the jet one in group $\mathrm{i}$, and $=1,2, \ldots \ldots, \mathrm{k}, \mathrm{i}=1, \ldots \ldots, \mathrm{n}$, here's the detailed calculating steps:

Step1: calculate the average $\overline{\mathrm{X}}_{j}$ and its standard deviation $\bar{\sigma}_{j}$;

Step2: calculate the coefficient of variation of every index, $\mathrm{V}_{j}=\frac{\bar{\sigma}_{j}}{\overline{\mathrm{X}}_{j}}$;

Step3: calculate the weight of every index, $\mathrm{W}_{j}=\frac{\mathrm{v}_{j}}{\sum_{j=1}^{k} \mathrm{v}_{j}}$.

\section{Train Operation Evaluation Model Based on DEA Method}

DEA has the advantage that the function relation between output and input is not considered, so it has lower requirements on the original data and stronger evaluation objectivity. But traditional DEA models cannot compare and rank all the efficient DMUs. This paper can solve this problem through the following procedure: firstly, the traditional model is applied to distinguish strong efficient, common efficient and non-efficient DMUs and rank the non-efficient ones at the same time; secondly, calculate a measurement to rank the strong and common efficient DMUs; finally, the three kind of DMUs will be ranked according to the principle that strong efficient DMUs are better than common efficient ones and the latter are better than non-efficient DMUs.

\subsection{Non-efficient DMUs Ranking Model.}

The traditional BCC model (input-oriented) shown in Equation 2 was used to select and rank nonefficient DMUs.

$$
\begin{gathered}
\theta_{o}^{*}=\operatorname{Min} \theta_{o} \\
\text { s.t. }\left\{\begin{array}{c}
\sum_{j=1}^{n} \lambda_{j} x_{i j}+s_{i o}^{-}=\theta_{o} x_{i o}, i=1,2, \ldots \ldots, \mathrm{m} \\
\sum_{j=1}^{n} \lambda_{j} y_{r j}-s_{r o}^{+}=y_{r o}, r=1,2, \ldots \ldots, \mathrm{s} \\
\sum_{j=1, j \neq b}^{n} \lambda_{j}=1 \\
s_{i o}^{-}, s_{r o}^{+} \geq 0 \\
s_{i o}^{-}, s_{r o}^{+}, \lambda_{j} \geq 0, \mathrm{j}=1,2, \ldots \ldots, \mathrm{n}
\end{array}\right.
\end{gathered}
$$


Where: $s_{i o}^{-}$and $s_{r o}^{+}$are the slack variable of the itch input and rah output ofDMU ${ }_{o}$. As forDMU , $_{o}$ the technique-scale efficiency $\theta_{o}^{*}$ can be obtained from the result of Eq. 2 , and it's easy to know that $\theta_{o}^{*} \in[0,1]$. If $\theta_{o}^{*}=1$, the $\mathrm{DMU}_{o}$ can be judged as efficient. Particularly, efficient DMUs can also be divided into two sorts: strong and common efficient. The $\mathrm{DMU}_{o}$ will be judged as strong efficient only if the value of every slack variable is 0 , otherwise it is a common efficient DMU. So, if $\theta_{o}^{*}<1$, the $\mathrm{DMU}_{o}$ is non-efficient, and the non-efficient DMUs can be compared and ranked by $\theta_{o}^{*}$, the bigger its value the better the $\mathrm{DUU}_{o}$.

\subsection{Efficient DMUs Ranking Model.}

\subsubsection{Strong Efficient DMU Ranking Model.}

Let $\mathrm{J}_{n}$ indicates the set of all the DMU. $\mathrm{J}_{b}$ Is any strong efficient DMU and $\mathrm{J}_{a}$ is a DMU from the set of non-efficient and common efficient DMUs, that is, $\mathrm{J}_{n}=\sum \mathrm{J}_{a}+\sum \mathrm{J}_{b}$.

If a $\mathrm{J}_{b}$ is removed from $\mathrm{J}_{n}$, any $\mathrm{J}_{a}$ will improve towards the more DEA-efficient situation, which is the reason why this paper only studies how an $\mathrm{J}_{b}$ influences $\mathrm{a} \mathrm{J}_{a}$. This paper uses the idea of literature [8] to calculate the $\rho_{a}^{*}$-efficiency(shown in Eq. 3) of $J_{a}$ and its new $\rho_{a, b}^{*}$-efficiency(shown in Eq. 4) after $\mathrm{J}_{b}$ is removed; the difference between $\rho_{a, b}^{*}$ and $\rho_{a}^{*}$, that is, $\rho_{a, b}^{*}-\rho_{a}^{*}$, as a measure of the influence $\mathrm{J}_{b}$ have on a $\mathrm{J}_{a}$, the bigger the value the more efficient the $\mathrm{J}_{b}$ is; and the influence of a $\mathrm{J}_{b}$ on all $\mathrm{J}_{a}, \Omega_{b}$ (shown in Eq. 5), is regarded as a comprehensive evaluation index, which is used as the ranking basis later.

$$
\begin{gathered}
\rho_{a}^{*}=\operatorname{Min} \alpha-\frac{\sum_{i=1}^{m} \overline{s_{i a}^{\bar{a}}}}{m}-\frac{\sum_{r=1}^{s} \frac{s_{r a}^{+}}{s}}{R_{r}^{+}} \\
\text {s.t. }\left\{\begin{array}{c}
-\sum_{j=1} x_{i j} \lambda_{j}+\alpha x_{i a}-s_{i a}^{-}=0, i=1, \ldots \ldots, m \\
\sum_{j=1} y_{r j} \lambda_{j}-y_{r a}-s_{r a}^{+}=0, r=1, \ldots \ldots, s \\
\sum_{j=1} \lambda_{j}=1 \\
\lambda_{j}, s_{i a}^{-}, s_{r a}^{+}, \alpha \geq 0 \\
\rho_{a, b}^{*}=M_{i n} \beta-\frac{\sum_{i=1}^{m} \frac{s_{i a}^{-}}{m}}{m}-\frac{\sum_{r=1}^{s} \frac{s_{r a}^{+}}{s}}{s} \\
\sum_{j \neq b} x_{i j}^{+} \lambda_{j}+\beta x_{i a}-s_{i a}^{-}=0, i=1, \ldots \ldots, m \\
\sum_{j \neq b} y_{r j} \lambda_{j}-y_{r a}-s_{r a}^{+}=0, r=1, \ldots \ldots, s \\
\sum_{j \neq b} \lambda_{j}=1 \\
\lambda_{j}, s_{i a}^{-}, s_{r a}^{+}, \beta \geq 0, \mathrm{j} \neq \mathrm{b} \\
\Omega_{b}=\sum_{a}\left(\rho_{a, b}^{*}-\rho_{a}^{*}\right)
\end{array}\right.
\end{gathered}
$$

\subsubsection{Common Efficient DMU Ranking Model.}

The method shown in Eq. 3, Eq. 4 and Eq. 5 are only useful for a strong efficient DMUs, so another method is applied here to evaluate common efficient ones. This paper uses the results of $s_{i o}^{-}$and $s_{r o}^{+}$ 
from Eq. 2 direct to calculate a new measure index $\delta_{o}$ as the comparing and ranking basis (Jahanshahloo G R et.al [9]), as shown as bellow.

$$
\delta_{o}=\frac{2-\frac{1}{m} * \sum_{i=1}^{m} \frac{s_{i o}^{-}}{x_{i o}}}{1+\frac{1}{s} * \sum_{r=1}^{s} \frac{s_{x_{o}}^{+}}{x_{r o}}}
$$

It's easy to know that smaller $s_{i o}^{-}$and $s_{r o}^{+}$means a better DMU. On the base of the original model, this paper adds 1 to the numerator, so the value of. $\delta_{o}$ Satisfies the condition of $\delta_{o} \epsilon(1,2)$, as a result, $\delta_{o}$ can be compared direct with $\theta_{o}^{*}$.

\section{Case Analysis}

\subsection{The Original Data of the Train Operation Schemes and its Processing.}

This paper researches on 10 train operation scheme of Beijing-Shanghai railway and compare the result with the method in literature [10]. $\mathrm{DMU}_{1}, \mathrm{DMU}_{7}$ and $\mathrm{DMU}_{10}$ aim at minimizing travel costs; $\mathrm{DMU}_{2}$ focuses on improving economic benefit and service; $\mathrm{DMU}_{3}$ is designed mainly from the operator's point of view; $\mathrm{DMU}_{4}$ take the benefits of the operator and travelers into account; $\mathrm{DMU}_{6}$ aims to reduce stop times; $\mathrm{DMU}_{5}$ and $\mathrm{DMU}_{8}$ take into consideration of economic, technology and service and $\mathrm{DMU}_{9}$ is a train operation scheme used in reality.

Since the case in this paper is aimed at a single railway line, not all the indexes are used here, that is, the waiting time, direct ratio, and transfer times are not taken into account. Because the requirement of degree of freedom is not satisfied here, original data dimension reduction is necessary in the pretreatment process. This paper integrates the two types of indicators according to the three attributes in the index system. As a result, the input or output indexes are transformed to a combination of a comprehensive economic index, a comprehensive technical index and a comprehensive service index. The result after pretreatment is shown in Table 3, which is applied in the case analysis afterwards.

Table 3. Preprocessed value of the DMUs.

\begin{tabular}{cccccc}
\hline \multicolumn{3}{c}{ Input } & \multicolumn{3}{c}{ Output } \\
\hline DMU & Economy X1 & Technology X2 & Economy Y1 & Technology Y2 & Service Y3 \\
1 & 940.53 & 150.26 & 2097.296 & 28016567.81 & 803.577 \\
2 & 2438.28 & 130.48 & 1820.326 & 16932428.22 & 788.593 \\
3 & 1580.025 & 129.66 & 2167.022 & 28016560.61 & 735.831 \\
4 & 1403.905 & 177.77 & 3744.302 & 101808141 & 855.544 \\
5 & 2027.84 & 140.01 & 2854.964 & 39277138.81 & 826.605 \\
6 & 2101.14 & 142.64 & 2854.079 & 39277157.66 & 823.775 \\
7 & 2636.93 & 132.85 & 333.653 & 49648404.61 & 772.805 \\
8 & 3682.802 & 235.53 & 9907.603 & 139396982.6 & 820.362 \\
9 & 3286.36 & 240.16 & 110.510 & 117985303.4 & 801.096 \\
10 & 925.45 & 150.42 & 1422.253 & 18430556.76 & 543.407 \\
\hline
\end{tabular}

\subsection{Calculation Results and Analysis.}

The results of $\theta_{o}^{*}$ and $\delta_{o}$ from Eel 2 and Eel 6 are shown in Table 4 and Table 5.

Table 4. $\Theta$-efficiency of the DMUs.

\begin{tabular}{ccccccccccc}
\hline DMU & 1 & 2 & 3 & 4 & 5 & 6 & 7 & 8 & 9 & 10 \\
\hline $\mathrm{S}_{1 o}^{-}$ & 0 & 0 & 0 & 0 & 0 & 49.2861 & 0 & 0 & 388.0714 & 0 \\
$\mathrm{~S}_{2 o}^{-}$ & 0 & 0 & 0 & 0 & 0 & 0 & 0 & 0 & 0 & 0 \\
$\mathrm{~S}_{1 o}^{+}$ & 0 & 0 & 0 & 0 & 0 & 0 & 0 & 0 & 6286.3013 & 0 \\
$\mathrm{~S}_{2 o}^{+}$ & 1.054 & 0.0107 & 0.0055 & 0 & 0 & 183326.3707 & 0 & 0 & 0.1906 & 0 \\
$\mathrm{~S}_{3 o}^{+}$ & 0 & 0 & 0 & 0 & 0 & 0 & 0 & 0 & 39.3064 & 0 \\
$\theta_{o}^{*}$ & 1 & 1 & 1 & 1 & 1 & 0.982 & 1 & 1 & 0.844 & 1 \\
property & $\mathrm{C}-\mathrm{E}$ & $\mathrm{C}-\mathrm{E}$ & $\mathrm{C}-\mathrm{E}$ & $\mathrm{S}-\mathrm{E}$ & $\mathrm{S}-\mathrm{E}$ & $\mathrm{N}-\mathrm{E}$ & $\mathrm{S}-\mathrm{E}$ & $\mathrm{S}-\mathrm{E}$ & $\mathrm{N}-\mathrm{E}$ & $\mathrm{S}-\mathrm{E}$ \\
\hline
\end{tabular}

Note: C-E indicates common efficient, S-E indicates strong efficient and N-E indicates non-efficient. 
Table 5. $\Delta$-efficiency of the common efficient DMUs.

\begin{tabular}{cccc}
\hline DMU & 1 & 2 & 3 \\
\hline$\delta_{0}$ & 1.99999996433 & 1.99999999954 & 1.999999999982 \\
\hline
\end{tabular}

Table 4 and 5 tell us that $\mathrm{DMU}_{6}>\mathrm{DMU}_{9}$ are non-efficient DMUs that shouldn't be accepted ("> $>$ means better than) and can be optimized in reality. Given the truth that $\mathrm{DMU}_{6}$ and $\mathrm{DMU}_{9}$ are designed from the view of minimum stop times, and other solutions are all the optimal design from different perspectives, the calculation result is rational. $\mathrm{DMU}_{3}>\mathrm{DMU}_{2}>\mathrm{DMU}_{1}$ Are all common-efficient DMUs which shouldn't be accepted in principle? $\mathrm{DMU}_{4}, \mathrm{DMU}_{5}, \mathrm{DMU}_{7}, \mathrm{DMU}_{8}$ and $\mathrm{DMU}_{10}$ are strong efficient ones that can be accepted if conditions permit; so, their relative merits should be further studied. The detailed ranking result from formula (3.2) - (3.4) is shown in Table 6.

Table $6 . \boldsymbol{\Omega}_{\boldsymbol{b}}$-efficiency of the strong efficient DMUs.

\begin{tabular}{cccccc}
\hline DMU & 4 & 5 & 7 & 8 & 10 \\
\hline$\Omega_{b}$ & 0.092866 & 0.07757 & 0.04128 & 0.489643 & 0.041478 \\
\hline
\end{tabular}

As shown in Table 4.4, the ranking of the five strong efficient DMUs is $\mathrm{DMU}_{8}>\mathrm{DMU}_{4}>$ $\mathrm{DMU}_{5}>\mathrm{DMU}_{10}>\mathrm{DMU}_{7}$, and so we can know the ranking of all the DMUs isDMU $8>\mathrm{DMU}_{4}>$ $\mathrm{DMU}_{5}>\mathrm{DMU}_{10}>\mathrm{DMU}_{7}>\mathrm{DMU}_{3}>\mathrm{DMU}_{2}>\mathrm{DMU}_{1}>\mathrm{DMU}_{6}>\mathrm{DMU}_{9}$. Considering economy, technology and service, the 8th train operation scheme is the best one that maximizes the comprehensive benefits and should be adopted at first; this is also compatible with the essence of $\mathrm{DMU}_{8}$ taking into account multiple benefits, that is, $\mathrm{DMU}_{8}$ is more rational. From the value of $\Omega_{b}$, it is easy to know that there is a significant difference between $\mathrm{DMU}_{8}$ and the other 4 strong efficient DMUs while they differ little from each other. So, we can see $\mathrm{DMU}_{8}$ has absolute advantage over the other four DMUs. This is the influence of the objects of these train operation schemes, different optimization goals will lead to different results. Since all the five ones are all strong efficient,DMU ${ }_{4}$, $\mathrm{DMU}_{5}, \mathrm{DMU}_{7}$ and $\mathrm{DMU}_{10}$ can be adopted successively when the reality not permit.

\subsection{Method Comparison.}

The results in this paper will be compared with that of the method in literature [10]. The method in [10] classifies strong and weak effective DMUs into one category and calculating their impact metrics on effective and non-efficient DMUs respectively; after integrating the two indicators, the final ranking is as shown in Table 7 below:

Table 7. The ranking results of the contrastive method.

\begin{tabular}{ccccccccccc}
\hline ranking & 1 & 2 & 3 & 4 & 5 & 6 & 7 & 8 & 9 & 10 \\
\hline $\mathrm{DMU}$ & $\mathrm{DMU}_{8}$ & $\mathrm{DMU}_{4}$ & $\mathrm{DMU}_{1}$ & $\mathrm{DMU}_{5}$ & $\mathrm{DMU}_{3}$ & $\mathrm{DMU}_{2}$ & $\mathrm{DMU}_{7}$ & $\mathrm{DMU}_{10}$ & $\mathrm{DMU}_{6}$ & $\mathrm{DMU}_{9}$ \\
\hline
\end{tabular}

The key of applying DEA method is effective DMUs analysis, so $\mathrm{DMU}_{6}$ and $\mathrm{DMU}_{9}$ can be excluded from consideration. Comparing the two sets of results, we can find that the two methods have the same judgment on efficient and non-efficient DMU classification but the ranking of the efficient ones is obviously different. By contrast, this paper researches the strong efficient, common efficient and non-efficient DMUs and integrate the results finally. Therefore, the results of the method in this paper is consistent with the principle of strong efficient better than common efficient better than non-efficient DMUs, which is not reflected in literature [10]. In literature [10], some of the common efficient ones are judged better than some strong efficient DMUs, and this can obviously prove the scientific, the ranking of the 5 strong efficient DMUs in the contrastive method is roughly consistent with that in this paper, so that can also prove that the method proposed in this paper is effective for the strong and effective DMU sorting method. 


\section{Summary}

There have been many researches on the application of DEA method in recent years, and the related models are being mature gradually. Since train operation scheme is a problem of multiple inputs and outputs, DEA is suitable for the evaluation and decision-making behaviors about it. Based on the existing researches, this paper proposes an evaluation and ranking method that includes all the strong efficient, common efficient and non-efficient DMUs, considering the requirements of the DEA method on the positive and negative indexes of the original data and the degree of freedom. In the meantime, it can also improve its application universality by selecting appropriate indexes according to the reality. Finally, the rationality of this model is verified through case analysis and method comparison. Therefore, the DEA-based model of train operation scheme evaluation proposed in this paper has practical guiding significance.

\section{Acknowledgements}

This paper was supported by the National Natural Science Foundation of China (No. 71231001).

\section{References}

[1]. Lingo Deng: Study on the Optimal Problems of Passenger Train Plan for Dedicated Passenger Traffic Line (Doctoral dissertation, Central South University, China, 2007).

[2]. Siu Tao: Research on Economic Returns Evaluation of Passenger Train Plan with Computer Realization (Master dissertation, East China Jiao tong University, China, 2006).

[3]. Aside, A., Grader, S. F., \& Izadbakhsh, H, Integration of dean and hap with computer simulation for railway system improvement and optimization, Applied Mathematics \& Computation, 195(2008).2, 775-785.

[4]. Song P U, Honiara L, Dynamic evaluation for train line planning in high speed railway based on improved data envelopment analysis, Journal of Computer Applications, 35(2015).5, 1479-1482.

[5]. Kulak, Osman, Karajan, \& Congas, Fuzzy multi-attribute selection among transportation companies using axiomatic design and analytic hierarchy process, Information Sciences, 170(2005).2, 191-210.

[6]. Xing fang X U, Cheng Y, Applicability Analysis of Two Evaluation Models of Intercity Train Scheduling, Journal of Tingyi University (Natural Science), 36(2008).1, 52-56.

[7]. Qu, Siouan, and X. Xu, Evaluation of Train Operation Plans of Intercity Railway Based on DEA, Journal of East China Jiao tong University, 29(2012).1, 79-85.

[8]. Hibachi, Norio, and T. Sue Yoshi, DEA sensitivity analysis by changing a reference set: regional contribution to Japanese industrial development, Omega, 27(1999).2, 139-153.

[9]. Jahanshahloo G R, Junior H V, Lofty F H, et al. A new DEA ranking system based on changing the reference set, European Journal of Operational Research, 181(2007).1, 331-337.

[10]. Du Juan, DEA-based Research on Ranking DMUs and Performance Measurement of Twostage Network Structures (Doctoral dissertation, University of Science and Technology of China, China, 2010). 